\title{
Fathers Are Parents, Too! Widening the Lens on Parenting for Children's Development
}

\author{
Natasha J. Cabrera, ${ }^{1}$ Brenda L. Volling, ${ }^{2}(\mathbb{D})$ and Rachel Barr ${ }^{3}$ \\ ${ }^{1}$ University of Maryland, ${ }^{2}$ University of Michigan, and ${ }^{3}$ Georgetown University
}

ABSTRACT-Why do fathers matter? Recent conceptual and theoretical advances regarding father-child relationships have demonstrated that fathers affect children's outcomes both directly and indirectly. To attain a complete developmental account of the ecologically rich contexts of child development, in this article, we recommend best practices regarding the conceptualization and assessment of father-child relationships that reflect contemporary family life. We also discuss conceptual and measurement issues pertaining to father-child relationships in different family configurations, including those with resident and nonresident fathers. We conclude with recommendations that can help developmental researchers advance our understanding of fathering, parenting, and children's development.

KEYWORDS-fathers; fathering; measurement; child outcomes

Significant global social, economic, and demographic changes over the last 40 years suggest that traditional mother-focused models of developmental influence are outdated and do not

Natasha J. Cabrera, Department of Human Development, University of Maryland; Brenda L. Volling, Department of Psychology, University of Michigan; Rachel Barr, Department of Psychology, Georgetown University.

This article is based on a June 2016 meeting sponsored by the Society for Research in Child Development, which brought together an interdisciplinary group of scholars studying fatherhood. The scholars' names appear in Supporting Information.

Correspondence concerning this article should be addressed to Natasha J. Cabrera, Professor of Human Development and Quantitative Methodology, 3942 Campus Drive, Suite 3304, University of Maryland, College Park, MD 20742-1131; e-mail: ncabrera@ umd.edu.

(C) 2018 The Authors

Child Development Perspectives $@ 2018$ The Society for Research in Child Development DOI: $10.1111 /$ cdep. 12275 represent the experiences of most children $(1,2)$. Children develop in a socially complex, ecological context where mothers and fathers exert influence over their growth and well-being (3). Yet research focuses almost exclusively on the mother-child dyad. Despite a surge of studies on fathers in recent decades, fathers more often than not contribute silently to children's development or are forgotten (4). Most studies of parenting neither include fathers nor control for fathers' effects on children's outcomes. And when fathers are included, measures of fathering are often derived from assessments of mothering, even though fathers may not engage in the same sorts of activities that characterize mother-child relationships. Also, we understand little about how parenting unfolds in diverse cultural contexts and different family structures, which has important implications for how mothers and fathers parent (5). Such differences underscore the complexities of family life and require researchers to think broadly about what it means to be a parent in the 21 st century.

In this article, we first discuss conceptual and theoretical thinking about the role of father-child relationships in children's development - specifically, why are fathers still absent from parenting research? Then we describe a contextual model of fatherhood and explain why fathers matter for children's outcomes. We also recommend best practices for assessing father-child relationships: How do we measure most effectively father-child relationships in different family configurations, including families in which fathers are resident and nonresident? Finally, we present guidelines for research to close gaps in how we assess the ways fathers influence their children's development.

\section{WHY ARE FATHERS STILL ABSENT FROM PARENTING RESEARCH?}

Given decades of evidence that fathers (and mothers) contribute independently to their children's well-being and development, the lack of systemic and rigorous integration of fathers into research on parenting is puzzling (6). We identify at least three reasons why this is so: First, the distinction between primary and secondary caregivers when referring to the quantity of time 
mothers and fathers spend with their children has made it easier to exclude fathers from research. Because fathers generally provide economically for their families, they are assumed to be less involved than mothers in interactions with children and thus not the primary parent at home. Similarly, nonresident fathers are seen as absent and not primary, and are not considered part of the complex network of caregivers who engage regularly with childrearing.

Designating mothers as primary caregivers makes it easier for parenting researchers to focus exclusively on mothers. Although most theories of parenting are intended to apply to both mothers and fathers, not just to the parent considered primary, these have not been used uniformly to understand mothers' and fathers' influence on their children's development (7). For instance, attachment theory, which allows for young children to have multiple caregivers, has been applied almost universally to relationships between mothers and infants (8), giving the impression that the mother-child bond is paramount, although this view has been challenged recently (9), and further solidifying the view that mothers are primary caregivers. Fathers are not the focus of most parenting research, which appears to be based on the theoretical biases that mothers are primary caregivers and fathers are secondary, that fathers are simply babysitters, or that they are part of relative care $(3,10)$.

Second, the belief that fathers do not engage in hands-on parenting (11), which is rooted in social norms about appropriate roles of men and women (i.e., social role theory), may also contribute to the absence of fathers in parenting research. For a long time, fathers have been characterized as being highly involved by providing for their children economically, but less involved in their daily care, leading to the conclusion that they do not spend enough time with their children to affect their lives emotionally (12). The focus on fathers' roles as providers has dominated sociological and economic research, suggesting that money matters more than emotional support for children's development (13). In spite of the fact that the effect sizes of fathers' financial contributions on children's development are consistent but small, researchers and policymakers have focused almost exclusively on and promoted fathers' economic provisions, and have disregarded fathers' emotional support of their children's development, especially for ethnic-minority low-income men.

Indeed, research on the quality of father-child relationships or father-child attachment pales in comparison to studies on men's role as economic providers (13). However, the notion that fathers are mostly economic providers and are not engaged in the emotional well-being of their children does not reflect the reality of the experiences of fathers and families today; this is the case especially in dual-earner households where both mothers and fathers work outside the home to support their families, and consequently both are actively involved in childrearing ( 1 , 14). Although mothers still do more household tasks than fathers (about $17 \mathrm{hr}$ per week compared to fathers' $10 \mathrm{hr}$ ), contemporary fathers are more involved in hands-on activities than they were in previous decades and consequently, are more involved in caring for their children, which affects their development (15, 16).

Third, amid significant social and demographic shifts in family composition over the last few decades in the United States and elsewhere, the almost exclusive focus on mothers in most parenting research reflects inaccurately the status of contemporary families. For example, over the last 40 years, family composition has shifted dramatically, resulting in changes in the living arrangements of children; today, $40 \%$ of all children in the United States are born to unwed mothers (17). But although family structures may change, having a nonresident father does not mean fathers are absent in their children's lives (18). Many nonresident fathers remain committed to and involved with their children, even when their relationship with the mother of the children has ended.

Developmental scientists need to move away from a predominant focus on quantity, the designation of a primary caregiver as the target parent for research, and a dyadic perspective that includes only mothers, and take a family systems' view that considers the family as a unit and the quality of interactions within a family system, including other subsystems such as interactions between fathers and children and among fathers, mothers, and children. We then need to translate this research into practice and draw clear implications of what it means for social policies. Although mothers still spend more time caring directly for their children than fathers, designating a caregiver as primary based on the time spent with children (quantity) has less importance and impact on children's development than considering the quality of the interaction during the time spent together (1). Most often, research on fathers suffers from the same limits as research on mothers. It does not always recognize that fathers are part of a network of caregivers; that others (e.g., mothers) influence children, too, and should be included; and that at the very least, the effect of mothers' parenting should be controlled. Studies that include both parents are beginning to appear but are still not the norm (19-23).

\section{CONCEPTUALIZING FATHERS AS PART OF FAMILY SYSTEMS}

Although there is no grand theory of fathering, developmental scientists have at their disposal a tool kit that includes ecologically based models that view families as an integrated system of subsystems that include fathers $(3,7)$. Models of fathering (e.g., the Ecology of Father-Child Relationships: An Expanded Model; 3) recognize the diversity of family life and the changing patterns of fathering, the personal motivation to father, the parental characteristics that predict fathering, and the overall context of parenting within a family system (2). Current models (3), informed by recent research showing the importance of context to understanding what fathers do and why it matters for children, tend to be grounded in dynamic systems and transactional 
concepts that evolve through time and cultural contexts $(3,23$, 24). In these models, children participate actively in their own development and fathers' behaviors are related to children's behaviors directly and indirectly through other family relationships and contextual factors such as frequency and quality of contact. Recent studies have begun to look at fathers from a family and developmental systems perspective $(25,26)$. Many models have also begun to incorporate aspects of the cultural context that may play out differently for mothers and fathers, as well as for parents of different ethnic groups $(20,24)$.

\section{HOW DO FATHERS MATTER FOR CHILDREN?}

In studies that have tested for direct effects, fathers influence children's development across many domains through direct interactions or by providing children with educational materials to enhance their learning and development (27). Fathers' social class - their education and income - is associated uniquely and directly with paternal sensitivity during interactions as well as with measures of children's cognitive and language abilities, suggesting that fathers with more education have children who have greater scores on such tests $(2,5,19$, 28). Additionally, across socioeconomic status, race, and ethnicity, sensitive and supportive fathers have children who are socially competent and have positive friendships in school settings $(29,30)$, and who engage in more complex play and have more optimal language outcomes $(31,32)$.

Depending on fathers' level of involvement, they can affect children's development positively even when they do not live with them (1). Although nonresident fathers spend significantly less time with their children than resident fathers, the quality of interactions predicts outcomes, not the quantity (1). While the complete absence of a father is associated with less success in school, impaired cognitive function, aggression, and delinquency in children (12), children who have contact with their fathers (regardless of the residency status of the father) regulate their emotions more effectively than children who have no contact (33).

In studies on indirect effects, fathers also influence their children through the investments of time (parent-child interactions) and money that result in improvements to the quality of children's home experiences $(10,25,26)$. Fathers also influence children through the relationship they have with their children's mother, whether through marital or coparental interactions (25, 26), or fathers' mental health, conflict with mothers, and the stresses brought home from work (14), all of which can harm parenting behaviors (34). Fathers' mental health is often overlooked, despite the fact that the transition to parenthood places men at risk for depression, especially for low-income minority men (34), which is likely to affect the entire family system, including fathers, their partners, and their children. The relationship between parents also matters, and supportive coparenting is associated with fewer behavior problems and greater selfregulatory skills in children $(21,22,26,35)$.

\section{NEW APPROACHES TO MEASURING FATHER-CHILD RELATIONSHIPS IN CONTEMPORARY FAMILIES}

The studies we have described used many types of assessment, including survey methods and video-recorded interactions between fathers and children (although this is much rarer), to understand variations in father-child relationships. Most father-child assessment measures and parenting surveys were developed to assess mother-child relationships and mothering behaviors. This practice is a reasonable first step in understanding parenting practices as it may tap behaviors and strategies that are universal across parents (e.g., sensitive responsiveness, caregiving). Moving beyond the maternal template will necessitate using many methods, including qualitative methods (e.g., focus groups, qualitative interviews) that enable researchers to uncover how fathers interact with and relate to their children, and how they engage in different activities.

Fagan and colleagues (18) took this approach in developing a new assessment of nonresident father involvement that focused on the quality of father-child relationships. Their measure asks fathers how often they have face-to-face contact with their children, how often they connect with their children through telephone calls and social media, how often they spend the night with their children, and what types of activities they engage in with their children. Similarly, observational studies of the manner in which fathers (not just mothers) prefer to interact with their children may provide additional insights into parenting practices that have not been examined adequately. For example, compared to mothers, fathers are more likely to tease their children, encourage them to take calculated risks, and engage in rough and tumble play (36). The quality of fathers' rough and tumble play has been implicated in the development of children's social skills and regulatory behaviors (36). But assuming that only fathers engage in this type of play is as inaccurate as assuming that only mothers provide emotional support to their children or that only fathers provide economic support. Rough and tumble play has been examined almost exclusively in the context of father-child relationships, although mothers also engage in it. This narrow approach then perpetuates biases about fathering behavior such as those seen in studies that focus exclusively on mothers (e.g., rough and tumble play is important for children when done by fathers).

Embracing the paternal template to study parenting behaviors might be as ecologically invalid as embracing just the maternal template. We need a comprehensive methodological approach firmly grounded in theory that guides research on parenting to capture a broad array of mothering and fathering behaviors, including behaviors similar for both parents, more prevalent at a specific time, done by a specific parent, and that produce specific outcomes. We may need to develop new paradigms to determine how mothers and fathers are similar, different, complementary, or additive, and that apply to specific outcomes and points in development (37). 
Including neuroscience in understanding caregiving behaviors holds promise. We know that during the transition to parenting, mothers' and fathers' brains are plastic and adapt to parenting by significantly remodeling neural networks regulated by a complex array of hormonal changes, which are associated with increased vigilance and social-emotional engagement (38). Although changes to networks after the start of parenthood are similar, neural networks also differ in mothers and fathers (39).

In adopting these approaches, we need to be aware of potential pitfalls and challenges. Neuroscience research that includes only one parent, say fathers, risks drawing premature conclusions that may not represent the complete experiences of the father or the child in a network of caregivers. For example, in recent neuroscience studies, fathers' brains responded differently to daughters than sons; fathers spent time in rough and tumble play and in conversation differently with their sons and their daughters, and some fathers were more sensitive to their daughters' emotional needs than to their sons' (40). These findings are intriguing, but are they unique to fathers, or do they apply to mothers and other caregivers, too? How does the context of childrearing (e.g., one parent vs. two parents) influence brain architecture? Research on the parental brain and its role in the development of father-child and mother-child relationships will advance only when we include contextual variables and both parents in neuroscience studies.

Moving forward, embracing a broader set of methods that focus on parenting behaviors that fathers may do more than mothers (e.g., engaging in rough and tumble play, challenging behavior, or encouraging risk taking) or that mothers may do more than fathers (e.g., calming, soothing) will lead to a deeper understanding of fathering as well as mothering, and may provide a window into new parenting constructs $(6,18)$. Logically, this approach argues for including multiple assessments of mothers and fathers, such as observations in different paradigms and self-report measures of parenting using new constructs (37) so parenting does not simply reflect one reporter, one method, or one parent's behavior. Furthermore, mothers' and fathers' joint influence on children should be analyzed simultaneously rather than independently so research is more sensitive to the systemic, dependent nature of family systems (41). Finally, taking this approach argues for including in sufficient numbers both mothers and fathers in large-scale health-surveillance surveys (34) and representative longitudinal studies (6). These studies should feature observations of dyadic (father-child and motherchild) and triadic (father-child-mother) interactions.

\section{CONCLUSION}

We urge researchers to adopt a family systems approach that considers how both parents interact with their children, as well as what types of behaviors are more prevalent for which parent and for which domains of development. This specificity in linking fathering and mothering processes to children's development can shed light on how each parent individually and together contributes to children's development. Research is slowly moving in this direction. New interventions for fathers have significantly enhanced the quality of father-child interactions and paternal self-efficacy (42-44), and coparenting interventions have reduced mothers' and fathers' parenting stress and symptoms of depression, and have enhanced parenting quality (21, 22).

Moreover, our family systems models need to acknowledge that fathers are parents, too, and that studies that include only mothers are not studies on parenting but rather studies on mothering. We cannot claim as a society that we care about children and parents, and then say as researchers that we exclude fathers in studies because of a lack of resources or the complexity of family life. We have the theoretical models and the tools to conduct research that includes both parents. We now need the commitment and social will (e.g., federal and state funding of parenting programs) to include both mothers and fathers in our research and interventions. Only then can we consider not only the direct and indirect effects of parents' behaviors on children's outcomes, but also the complexity of parenting and the interactive and joint contributions of mothers and fathers to children's development.

\section{REFERENCES}

1. Cabrera, N., Tamis-LeMonda, C. S., Bradley, R. H., Hofferth, S., \& Lamb, M. E. (2000). Fatherhood in the twenty-first century. Child Development, 71, 127-136. https://doi.org/10.1111/1467-8624. 00126

2. Kalil, A., Ryan, R., \& Chor, E. (2014). Time investments in children across family structures. The Annals of the American Academy of Political and Social Science, 654, 150-168. https://doi.org/10.1177/ 0002716214528276

3. Cabrera, N. J., Fitzgerald, H. E., Bradley, R. H., \& Roggman, L. (2014). The ecology of father-child relationships: An expanded model. Journal of Family Theory and Review, 6, 336-354. https://d oi.org/10.1111/jftr.12054

4. Lamb, M. E. (1975). Fathers: Forgotten contributors to child development. Human Development, 18, 245-266. https://doi.org/10.1159/ 000271493

5. Ryan, R. M., Claessens, A., \& Markowitz, A. J. (2015). Associations between family structure change and child behavior problems: The moderating effect of family income. Child Development, 86, 112127. https://doi.org/10.1111/cdev.12283

6. Fagan, J., Day, R., Lamb, M. E., \& Cabrera, N. J. (2014). Should researchers conceptualize differently the dimensions of parenting for fathers and mothers? Journal of Family Theory and Review, 6, 390405. https://doi.org/10.1111/jftr.12044

7. Bronfenbrenner, U., \& Morris, P. A. (2007). The bioecological model of human development. In W. Damon (Series Ed.) \& R. M. Lerner (Vol. Ed.), Handbook of child psychology: Theoretical models of human development (pp. 793-828). New York, NY: Wiley.

8. Palm, G. (2014). Attachment theory and fathers: Moving from "being there" to "being with." Journal of Family Theory and Review, 6, 282-297. https://doi.org/10.1111/jftr.12045 
9. Cassidy, J., Jones, J. D., \& Shaver, P. R. (2013). Contributions of attachment theory and research: A framework for future research, translation, and policy. Development and Psychopathology, 25, 1415-1434. https://doi.org/10.1017/S0954579413000692

10. Palkovitz, R. (2002). Involved fathering and men's adult development: Provisional balances. Mahwah, NJ: Erlbaum.

11. Eagly, A. H., \& Wood, W. (2017). Gender identity: Nature and nurture working together. Evolutionary Studies in Imaginative Culture, 1, 59-62. https://doi.org/10.26613/esic/1.1

12. Amato, P. R., \& Gilbreth, J. G. (1999). Nonresident fathers and children's well-being: A meta-analysis. Journal of Marriage and Family, 61, 557-573. https://doi.org/10.2307/353560

13. Duncan, G. J., Morris, P. A., \& Rodrigues, C. (2011). Does money really matter? Estimating impacts of family income on young children's achievement with data from random-assignment experiments. Developmental Psychology, 47, 1263-1279. https://doi.org/10.1037/ a0023875

14. Kuo, P. X., Volling, B. L., \& Gonzalez, R. (2017). Gender role beliefs, work-family conflict, and father involvement after the birth of a second child. Psychology of Men and Masculinity. Advance online publication. https://doi.org/10.1037/men0000101

15. Lachance-Grzela, M., \& Bouchard, G. (2010). More on the gendered division of household labor: A response to commentators. Sex Roles, 63, 801-806. https://doi.org/10.1007/s11199-010-9885-0

16. Sayer, L. (2016). Gender and couple relationships. Charm, Switzerland: Springer International.

17. Centers for Disease Control and Prevention. (2013). Foreword. CDC health disparities and inequalities report-United States, 2013. (PMID:24264482). Morbidity and Mortality Weekly Report, November 22, 2013 (Supplement, Vol. 62, No. 3). Retrieved from https:// www.cdc.gov/mmwr/pdf/other/su6203.pdf

18. Fagan, J., Kaufman, R., \& Dyer, J. (2017). Conceptualizing and measuring low-income, nonresident fathers' contact with children. Philadelphia, PA: Temple University.

19. Cabrera, N. J., Shannon, J. D., \& Tamis-LeMonda, C. (2007). Fathers' influence on their children's cognitive and emotional development: From toddlers to pre-k. Applied Developmental Science, 11, 208-213. https://doi.org/10.1080/10888690701762100

20. Endendijk, J. J., Groeneveld, M. G., van der Pol, L. D., van Berkel, S. R., Hallers-Haalboom, E. T., Bakermans-Kranenburg, M. J., \& Mesman, J. (2017). Gender differences in child aggression: Relations with gender-differentiated parenting and parents' gender-role stereotypes. Child Development, 88, 299-316. https://doi.org/10. 1111/cdev.12589

21. Feinberg, M. E., Jones, D. E., Roettger, M. E., Solmeyer, A., \& Hostetler, M. (2014). Long-term follow-up of a randomized trial of family foundations: Effects on children's emotional, behavioral, and school adjustment. Journal of Family Psychology, 28, 821-831. https://doi. org/10.1037/fam0000037

22. Schoppe-Sullivan, S. J., Weldon, A. H., Cook, J. C., Davis, E. F., \& Buckley, C. K. (2009). Coparenting behavior moderates longitudinal relations between effortful control and preschool children's externalizing behavior. Journal of Child Psychology and Psychiatry, 50, 698-706. https://doi.org/10.1111/j.1469-7610.2008.02009.x

23. Volling, B. L., Gonzalez, R., Oh, W., Song, J.-H., Yu, T., Rosenberg, L., ... Stevenson, M. (2017). Developmental trajectories of children's adjustment across the transition to siblinghood: Pre-birth predictors and sibling outcomes at one year. Monographs of the Society for Research in Child Development, 82(3, Serial No. 326), 1-216. https://doi.org/10.1111/mono.12265
24. Gettler, L. T. (2016). Becoming DADS: Considering the role of cultural context and developmental plasticity for paternal socioendocrinology. Current Anthropology, 57, S38-S51. https://doi.org/10. $1086 / 686149$

25. Cabrera, N. J., Shannon, J., Mitchell, S., \& West, J. (2009). Mexican American mothers and fathers' prenatal attitudes and father prenatal involvement: Links to mother-infant interaction and father engagement. Sex Roles, 60, 510-526. https://doi.org/10.1007/s11199-0089576-2

26. Kolak, A. M., \& Volling, B. L. (2013). Coparenting moderates the association between firstborn children's temperament and problem behavior across the transition to siblinghood. Journal of Family Psychology, 27, 355-364. https://doi.org/10.1037/a0032864

27. Flouri, E., \& Buchanan, A. (2004). Early father's and mother's involvement and child's later educational outcomes. British Journal of Educational Psychology, 74, 141-153. https://doi.org/10.1348/ 000709904773839806

28. Malin, J. L., Karberg, E., Cabrera, N. J., Rowe, M., Cristaforo, T., \& Tamis-LeMonda, C. S. (2012). Father-toddler communication in low-income families: The role of paternal education and depressive symptoms. Journal of Family Science, 3, 155-163. https://doi.org/ 10.1080/19424620.2012.779423

29. Cabrera, N. J., Cook, G. A., McFadden, K. E., \& Bradley, R. H. (2011). Father residence and father-child relationship quality: Peer relationships and externalizing behavioral problems. Family Science, 2, 109-119. https://doi.org/10.1080/19424620. 2011.639143

30. McDowell, D. J., \& Parke, R. D. (2009). Parental correlates of children's peer relations: An empirical test of a tripartite model. Developmental Psychology, 45, 224-235. https://doi.org/10.1037/ a0014305

31. Malin, J. L., Cabrera, N. J., \& Rowe, M. L. (2014). Low-income minority mothers' and fathers' reading and children's interest: Longitudinal contributions to children's receptive vocabulary skills. Early Childhood Research Quarterly, 29, 425-432. https://doi.org/ 10.1016/j.ecresq.2014.04.010

32. Roggman, L. A., Boyce, L. K., Cook, G. A., Christiansen, K., \& Jones, D. (2004). Playing with daddy: Social toy play, early head start, and developmental outcomes. Fathering, 2, 83-108.

33. Vogel, C. A., Bradley, R. H., Raikes, H. H., Boller, K., \& Shears, J. K. (2006). Relation between father connectedness and child outcomes. Parenting: Science and Practice, 6, 189-209. https://doi.org/ 10.1080/15295192.2006.9681305

34. Garfield, C. F., Duncan, G., Rutsohn, J., McDade, T. W., Adam, E. K., Levine Coley, R., \& Chase-Lansdale, P. L. (2014). A longitudinal study of paternal mental health during transition to fatherhood as young adults. Pediatrics, 133, 836-842. https://doi.org/10.1542/ peds.2013-3262

35. Karberg, E., \& Cabrera, N. (2017). Family change and co-parenting in resident couples and children's behavioral problems. Journal of Family Studies, 1-17. https://doi.org/10.1080/13229400.2017. 1367714

36. Fletcher, R., St George, J., \& Freeman, E. (2013). Rough and tumble play quality: Theoretical foundations for a new measure of father-child interaction. Early Child Development and Care, 183, 746-759. https://doi.org/10.1080/03004430.2012.723439

37. Majdandžić, M., Möller, E. L., de Vente, W., Bögels, S. M., \& van den Boom, D. C. (2014). Fathers' challenging parenting behavior prevents social anxiety development in their 4-year-old children: A longitudinal observational study. Journal of Abnormal 
Child Psychology, 42, 301-310. https://doi.org/10.1007/s10802013-9774-4

38. Feldman, R. (2015). The adaptive human parental brain: Implications for children's social development. Trends in Neurosciences, 38 , 387-399. https://doi.org/10.1016/j.tins.2015.04.004

39. Abraham, E., Hendler, T., Shapira-Lichter, I., Kanat-Maymon, Y., Zagoory-Sharon, O., \& Feldman, R. (2014). Father's brain is sensitive to childcare experiences. Proceedings of the National Academy of Sciences of the United States of America, 111, 9792-9797. https://doi.org/10.1073/pnas.1402569111

40. Mascaro, J. S., Rentscher, K. E., Hackett, P. D., Mehl, M. R., \& Rilling, J. K. (2017). Child gender influences paternal behavior, language, and brain function. Behavioral Neuroscience, 131, 262-273. https://doi.org/10.1037/bne0000199

41. Kashy, D. A., \& Kenny, D. A. (1990). Analysis of family research designs: A model of interdependence. Communication Research, 17, 462-482. https://doi.org/10.1177/009365090017004004

42. Barr, R., Morin, M., Brito, N., Richeda, B., Rodriguez, J., \& Shauffer, C. (2014). Delivering services to incarcerated teen fathers: A pilot intervention to increase the quality of father-infant interactions during visitation. Psychological Services, 11, 10-21. https://doi.org/ 10.1037/a0034877
43. Cabrera, N., \& Reich, S. (2017, April). BabyBooks2: A randomized control trial (RCT) to test the effects of a book intervention for lowincome mothers and fathers. In N. Cabrera (Chair), International perspectives on parenting interventions for at-risk families. Symposium conducted at the biennial meeting of the Society for Research in Child Development, Austin, TX.

44. Chacko, A., Fabiano, G. A., Doctoroff, G. L., \& Fortson, B. (2017). Engaging fathers in effective parenting for preschool children using shared book reading: A randomized controlled trial. Journal of Clinical Child and Adolescent Psychology, 1-14. https://doi.org/10.1080/ 15374416.2016.1266648

\section{SUPPORTING INFORMATION}

Additional supporting information may be found in the online version of this article:

Appendix S1. Working Group on Advancing Research on Fathers (convened June 2016) 